RoseMarie M. Rine, PhD

Michael C. Schubert,

$\mathrm{PhD}$

Susan L. Whitney, PhD

Dale Roberts, MS

Mark S. Redfern, PhD

Mark C. Musolino, PhD

Jennica L. Roche, MS

Daniel P. Steed, MS

Bree Corbin, MS

Chia-Cheng Lin, MS

Greg F. Marchetti, PhD

Jennifer Beaumont, MS

John P. Carey, MD

Neil P. Shepard, PhD

Gary P. Jacobson, PhD

Diane M. Wrisley, PhD

Howard J. Hoffman, MA

Gabriel Furman

Jerry Slotkin, $\mathrm{PhD}$

Correspondence to

Dr. Rine:

specialtytherapy@bellsouth.net

\title{
Vestibular function assessment using the NIH Toolbox
}

\section{ABSTRACT}

Objective: Development of an easy to administer, low-cost test of vestibular function.

Methods: Members of the NIH Toolbox Sensory Domain Vestibular, Vision, and Motor subdomain teams collaborated to identify 2 tests: 1) Dynamic Visual Acuity (DVA), and 2) the Balance Accelerometry Measure (BAM). Extensive work was completed to identify and develop appropriate software and hardware. More than 300 subjects between the ages of 3 and 85 years, with and without vestibular dysfunction, were recruited and tested. Currently accepted gold standard measures of static visual acuity, vestibular function, dynamic visual acuity, and balance were performed to determine validity. Repeat testing was performed to examine reliability.

Results: The DVA and BAM tests are affordable and appropriate for use for individuals 3 through 85 years of age. The DVA had fair to good reliability $(0.41-0.94)$ and sensitivity and specificity (50\%-73\%), depending on age and optotype chosen. The BAM test was moderately correlated with center of pressure ( $r=0.42-0.48)$ and dynamic posturography $(r=-0.48)$, depending on age and test condition. Both tests differentiated those with and without vestibular impairment and the young from the old. Each test was reliable.

Conclusion: The newly created DVA test provides a valid measure of visual acuity with the head still and moving quickly. The novel BAM is a valid measure of balance. Both tests are sensitive to age-related changes and are able to screen for impairment of the vestibular system. Neurology ${ }^{\circledR}$ 2013;80 (Suppl 3):S25-S31

\section{GLOSSARY}

$\mathbf{B A M}=$ Balance Accelerometry Measure; $\mathbf{C O P}=$ center of pressure; $\mathbf{D S}=$ double-limb feet together stance; $\mathbf{D V A}=$ dynamic visual acuity; ETDRS = Early Treatment Diabetic Retinopathy Study; ICC = intraclass correlation coefficient; logMAR = logarithm of the minimum angle of resolution; NPL = normalized path length; SOT = sensory organization testing; SVA = static visual acuity; TS = tandem stance; VH = vestibular hypofunction; VOR = vestibulo-ocular reflex; VSP = vestibulospinal outputs.

The vestibular system is an integral component of our sensory experience and sensory-motor function. Healthy peripheral and central vestibular anatomy is essential for functionally relevant gaze stability during head motion and postural control. ${ }^{1}$ However, gaze stabilization and balance are enabled by multiple sensory inputs (e.g., visual, somatosensory, and vestibular), integration and interpretation of these redundant sources of orientation, and motor output, each of which may be affected by age or damage. ${ }^{1-4}$ Patients with vestibular pathology often report oscillopsia (due to gaze instability), imbalance, and/or vertigo. The redundancy of the sensory information confounds distinction of the causal mechanisms of oscillopsia and/or imbalance. However, the unique contributions of the vestibulo-ocular reflex (VOR) and vestibulospinal outputs (VSP) to gaze stability and balance, respectively, can direct the identification of tests to screen for pathology of the vestibular system.

From the Specialty Therapy Source LLC (R.M.R., B.C.), Jacksonville, FL; Departments of Otolaryngology Head and Neck Surgery (M.C.S., J.P.C.) and Neurology (D.R.), John Hopkins School of Medicine, Baltimore, MD; Departments of Physical Therapy (S.L.W., C.-C.L.) and Bioengineering (M.S.R., J.L.R., D.P.S.) and College of Arts and Sciences (G.F.), University of Pittsburgh, Pittsburgh, PA; Crossroads Consulting, LLC (M.C.M.), Johnstown, PA; Department of Physical Therapy (G.F.M.), Duquesne University, Pittsburgh, PA; Department of Medical Social Sciences (J.B., J.S.), Northwestern University, Chicago, IL; Department of Otorhinolaryngology (N.P.S.), Vestibular and Balance Laboratory, Mayo Clinic, Rochester MN; Department of Hearing and Speech Sciences (G.P.J.), Division of Audiology, Vanderbilt University Medical Center, Nashville, TN; Department of Physical Therapy (D.M.W.), Lynchburg College, Lynchburg, VA; Epidemiology and Statistics Program (H.J.H.), National Institute on Deafness and Other Communication Disorders, NIH, Bethesda, MD; and Rehabilitation Research Chair (S.L.W.), King Saud University, Riyadh, Saudi Arabia.

Go to Neurology.org for full disclosures. Funding information and disclosures deemed relevant by the authors, if any, are provided at the end of the article. 
The semicircular canals and otolith end organs are the primary contributors to the VOR and VSP, respectively, but not exclusively. Damage to either of these organs will lead to unique impairments. Investigators have reported that patients with canal dysfunction have impaired dynamic visual acuity (DVA), ${ }^{5-12}$ and damage to the vestibulospinal system causes postural control impairment. ${ }^{13-16}$ Furthermore, adults and children with unilateral or bilateral vestibular dysfunction fail balance tests that require resolution of sensory conflicts regarding posture and that rely primarily on vestibular afference. ${ }^{3,17-20}$

Based on a comprehensive review of available tests and the literature, the NIH Toolbox Vestibular Team (R.M.R., M.C.S., S.L.W., J.P.C., N.P.S., G.P.J., D.M.W.) decided to include one test that attempts to isolate the vestibular system's contribution to gaze stability (indirect measure of the VOR), and one that attempts to isolate the vestibular system's contribution to postural control (indirect measure of VSP). Most tests were excluded because of 1) reliance on self-report of symptoms, 2) high cost, 3) requirement of expertise to administer and interpret, and/or 4) lack of sensitivity, validity, or reliability.

Figure 1 Rate sensor attached to headband and hat for monitoring rate of head movement

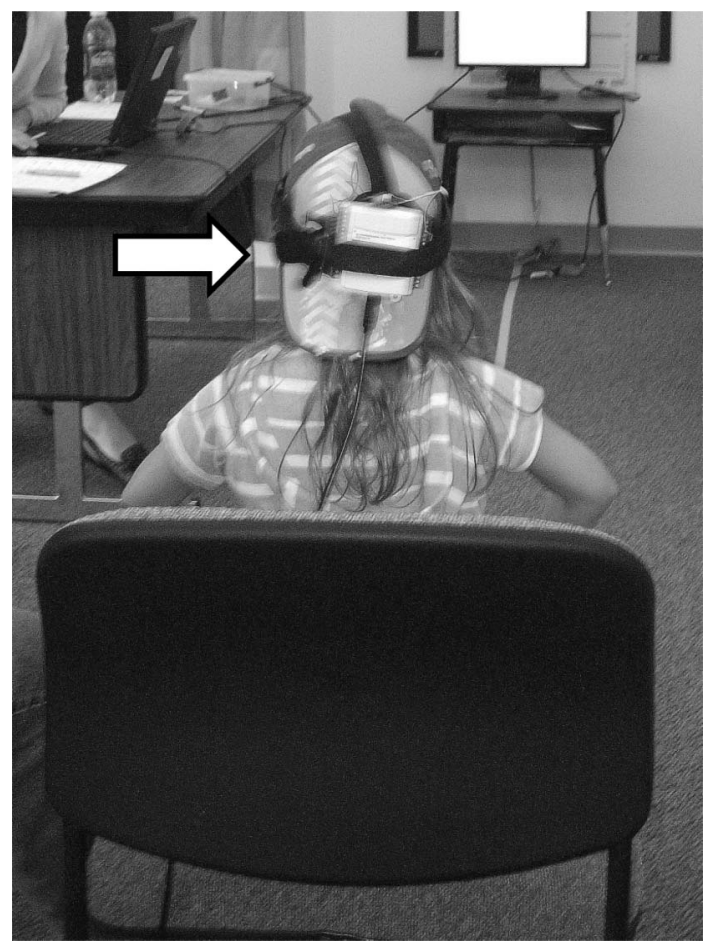

The team selected 2 tests: the Dynamic Visual Acuity test and a Balance Accelerometry Measure (BAM) (a modification of the Clinical Test of Sensory Interaction for Balance. ${ }^{20}$ Furthermore, it was agreed that the static component (static visual acuity [SVA]) of the DVA and BAM would be used as part of vision testing and as the NIH Toolbox Motor Domain balance measure, respectively. Although both the DVA and balance measures have a well-established history of use clinically and for research, clinical versions require expertise and have limited sensitivity and specificity. Well-established, existing computerized versions that quantify the DVA and postural control are expensive. Thus, new versions of these tests were developed, modified, and validated for inclusion in the NIH Toolbox.

METHODS DVA test. Equipment. A low-cost computerized test that minimizes motor, language, and cultural effects was developed (R.M.R., M.C.S., D.R., B.C., J.B., J.S.). ${ }^{21}$ Custom software was written in Python and $\mathrm{C}++$. Hardware included a 2-GHz Intel dual central processing unit laptop with $2 \mathrm{~GB}$ of RAM (IBM Thinkpad; IBM, Armonk, NY). The laptop was connected to a $1440 \times 900$ resolution monitor that displayed the optotypes. The operator used the built-in laptop display. For the head motion subtest, a single-axis rate sensor (O-Navi, Vista, CA) for detecting horizontal head rotation was attached to a soft bicycle light strap and secured to the head (figure 1). The rate sensor triggered the software to flash an optotype only when head velocity met or exceeded $180^{\circ}$ per second.

Technique. The test required an individual to identify an optotype (letter or symbol) presented one at a time at progressively smaller sizes. Subjects sat $12.5 \mathrm{ft}$ away from the viewing screen at their eye level. An initial "quick" screening of SVA was completed starting at size 20/50 and presenting a single random letter per acuity size (steps of 0.1 logarithm of the minimum angle of resolution $[\log M A R])$, either going smaller until one was identified incorrectly or larger until one was identified correctly.

Next we collected the subjects' static and dynamic visual acuity scores. For SVA, the head was kept stationary. For DVA, the subject actively moved his or her head to the left and right, but we were able to uniquely flash an optotype for rotations to one side only, enabling us to determine a DVA score for left and right rotations. Five optotypes per size were presented. Static testing trials began at 20/80 and continued through to identify the smallest size for which all 5 optotypes were correctly identified (minimal size to accurately identify all optotypes at a size) and the smallest size for which at least 3 of 5 optotypes were correctly identified (the minimal size to accurately identify the majority of optotypes at a size). The trial stopped automatically when these criteria were met. Dynamic testing was performed similarly, except the trial started at 3 sizes above the static acuity level. Additionally, all children completed training trials as described previously ${ }^{21}$ to assure proper head movement; testing proceeded when $80 \%$ success was achieved in training. During dynamic testing, the optotypes appeared only if the head moved $>180^{\circ}$ per second (monitored by a rate sensor on a headband; figure 1). All subjects were encouraged to guess even if they were not confident (i.e., forced-guess paradigm). Retesting was completed on 
Table 1 Reliability of static and dynamic acuity scores by age

\begin{tabular}{|c|c|c|c|c|c|c|c|}
\hline \multirow[b]{2}{*}{ Age, y } & \multirow[b]{2}{*}{ No. } & \multicolumn{2}{|l|}{ Lea } & \multicolumn{2}{|l|}{ HOTV } & \multicolumn{2}{|l|}{ ETDRS } \\
\hline & & $\begin{array}{l}\text { Static } \\
\text { ICC }^{\mathrm{b}}\end{array}$ & $\begin{array}{l}\text { Dynamic } \\
\text { ICC }\end{array}$ & $\begin{array}{l}\text { Static } \\
\text { ICC }\end{array}$ & $\begin{array}{l}\text { Dynamic } \\
\text { ICC }\end{array}$ & $\begin{array}{l}\text { Static } \\
\text { ICC }\end{array}$ & $\begin{array}{l}\text { Dynamic } \\
\text { ICC }\end{array}$ \\
\hline $3-4$ & 25 & $0.71^{a}$ & 0.05 & $0.75^{a}$ & $0.49^{a}$ & - & - \\
\hline $5-6$ & 27 & $0.80^{a}$ & $0.43^{a}$ & $0.66^{a}$ & $0.52^{a}$ & - & - \\
\hline 7-12 & 136 & $0.92^{a}$ & $0.26^{a}$ & $0.94^{a}$ & $0.46^{a}$ & $0.85^{a}$ & $0.41^{a}$ \\
\hline $13-17$ & 24 & - & - & - & - & $0.75^{a}$ & $0.73^{a}$ \\
\hline $18-75$ & 24 & - & - & - & - & $0.84^{\mathrm{a}}$ & $0.79^{a}$ \\
\hline
\end{tabular}

Abbreviations: ETDRS $=$ Early Treatment Diabetic Retinopathy Study; ICC $=$ intraclass correlation coefficient.

a Significance level $p \leq 0.05$.

${ }^{\mathrm{b}}$ ICC is an assessment of the consistency of measurements made by an instrument.

the same day within 1 hour by 53 adults and within 5 to 10 days by 246 children.

Scores were determined from each subject performing a single SVA test and 2 DVA tests (right and left). ${ }^{21}$ The difference in $\log$ MAR scores achieved on the static and dynamic conditions is the DVA score (calculated separately for leftward and rightward rotations), which represents the vestibular contribution to gaze stability.

We determined the age at which letters vs symbols were most effective, valid, and reliable for testing visual acuity. To identify the optimal optotypes for use with children, subjects younger than 13 years were tested using different optotype sets (Lea, HOTV, and Early Treatment Diabetic Retinopathy Study [ETDRS] test ${ }^{22,23}$; table 1) in a single session without rest. Sequence of optotype set presentation was assigned in a random block design to control for the effects of fatigue and/or boredom.

Subjects without ( $\mathrm{n}=301 ; 51 \%$ female, $49 \%$ male) and with ( $\mathrm{n}=17 ; 59 \%$ female, $41 \%$ male) vestibular hypofunction $(\mathrm{VH})$ (bilateral or unilateral, confirmed by rotary and/or caloric tests) participated. Ocular motor examination and medical history review was completed to ensure that exclusion criteria were met: central or peripheral nervous system pathology (except vestibular), oculomotor weakness, cognitive deficit, and pregnancy.

\section{Table 2 Reliability of BAM across age groups ${ }^{\mathrm{a}}$}

\begin{tabular}{|c|c|c|c|c|c|c|c|}
\hline \multirow[b]{2}{*}{ Age, y } & \multirow[b]{2}{*}{ No. } & \multicolumn{6}{|l|}{ ICC } \\
\hline & & BAM-1 & BAM-2 & BAM-3 & BAM-4 & BAM-5 & BAM-6 \\
\hline 3-8.5 & 45 & \multicolumn{6}{|c|}{ Unable because of lack of variance } \\
\hline 8.6-17 & 62 & 0.82 & 0.88 & 0.97 & 0.87 & 0.97 & 0.73 \\
\hline 18-35 & 31 & 0.72 & 0.56 & 0.33 & 0.79 & 0.34 & 0.48 \\
\hline $36-65$ & 41 & 0.89 & 0.74 & 0.73 & 0.82 & 0.83 & 0.27 \\
\hline $66-85$ & 29 & 0.87 & 0.86 & 0.88 & 0.87 & 0.87 & 0.06 \\
\hline 3-17 & 107 & 0.82 & 0.87 & 0.97 & 0.87 & 0.95 & 0.70 \\
\hline $18-85$ & 101 & 0.86 & 0.83 & 0.74 & 0.77 & 0.82 & 0.36 \\
\hline
\end{tabular}

Abbreviations: $\mathrm{BAM}=$ Balance Accelerometry Measure; $\mathrm{ICC}=$ intraclass correlation coefficient.

aAM conditions: 1 = eyes open, stand on firm surface, 2 = eyes closed, stand on firm surface, 3 = eyes open, stand on dense foam, 4 = eyes closed, stand on dense foam, $5=$ eyes open in tandem stance on firm surface, 6 = eyes closed in tandem stance on firm surface. Although the number of adults completing any condition was 101 (normal + patients), the valid $n$ changes between conditions because of a loss of balance/incomplete trial. ICC is an assessment of the consistency of measurements made by an instrument. Significance level $p \leq 0.05$.
SVA was also tested using the gold standard ETDRS testing using backlit (lightbox) charts to enable examination of validity. ${ }^{23}$

Statistical analysis. Descriptive statistics were calculated to summarize subject characteristics and completion rates. SVA scores were correlated with scores obtained using the lightbox technique to assess validity of the static test. Success rates on each optotype set and correlations among optotypes were examined to determine the optimal optotype for use with children. To examine validity of the DVA, scores from subjects with and without VH were compared using a $t$ test, adult DVA scores obtained here were compared with scores on a previously validated and reliable computerized DVA test using a $t$ test, ${ }^{5}$ and sensitivity and specificity were calculated. Test-retest reliability was assessed using intraclass correlation coefficients (ICCs).

Balance Accelerometry Measure. Equipment. Accelerometers have been used to assess postural control ${ }^{24}$ in older adults and to identify early symptoms of Parkinson disease. ${ }^{25} \mathrm{~A}$ low-cost tool that quantifies postural sway using an accelerometer was developed by team members at the University of Pittsburgh. ${ }^{26}$ A dual-axis accelerometer (ADXL213AE, \pm 1.2 g; Analog Devices, Inc., Norwood, MA) was chosen for its low-frequency characteristics and because it was designed to optimally record mediolateral and anteroposterior acceleration of the pelvis/trunk during standing. The accelerations are transmitted wirelessly using 16-bit bluetooth transmission at $100 \mathrm{~Hz}$. Full description of hardware and algorithms used are available in a previous report. ${ }^{26}$

Technique. Initially, 26 standing test positions/conditions were explored; the most difficult was a single leg stance on a dense foam pad with eyes closed while moving the head in the yaw plane at approximately $2 \mathrm{~Hz}$. The reliability and feasibility of measuring accelerations of the pelvis for the various conditions was evaluated. Six conditions were chosen to measure vestibulospinal function during standing, which the team believed had the potential to differentiate persons by age, and yet be completed by most participants across the age span. These include doublelimb feet together stance (DS) or tandem stance (TS) under varied vision and surface conditions: 1) eyes open on a solid floor DS, 2) eyes closed on a solid floor DS, 3) eyes open on dense foam DS, 4) eyes closed on dense foam DS, 5) eyes open on solid floor TS, and 6) eyes closed on solid floor TS. After testing several types of foam, the Airex balance pad (Advanced Medical Technology Inc., Watertown, MA) was chosen for the foam test condition. This pad created the greatest sway on a force plate compared with 2 other types of frequently used foam pads.

The BAM protocol was tested by the balance team (S.L.W., R.M.R., M.S.R., M.C.M., B.C., G.F.M., J.L.R., C.C.L., G.F., D.P.S., H.J.H., J.S.) using subjects of varying ages with and without vestibular pathology. Subjects between the ages of 3 and 85 years without $(\mathrm{n}=203)$ and with $(\mathrm{n}=25)$ VH were recruited, grouped by age (table 2), and tested. A medical history review, and somatosensory, vision, vestibular, and lower extremity strength screening were completed on all subjects to ensure compliance with exclusion criteria as noted above.

All subjects were asked to stand quietly for 70 seconds, and to look at a symbol or picture placed centrally at eye height, in eyes-open conditions. The first 5 seconds of data were discarded to ensure stability of measures, yielding 65 seconds of data for analysis. The normalized path length (NPL) (mG/s; higher values indicate more sway) of the acceleration time series calculated was used for scoring and analyses. Concurrent measures of center of pressure (COP) were obtained from a force plate. For the adults, the BAM was placed anteriorly around the waist using a gait belt. To prevent children younger than 13 years from disrupting the apparatus, the accelerometer was placed posteriorly (figure 2). All subjects were given 3 attempts to complete 1 trial of each condition. Repeat testing was performed by 
Figure 2 Accelerometer attached to gait belt and placed anteriorly on adults (A), posteriorly on children (B)
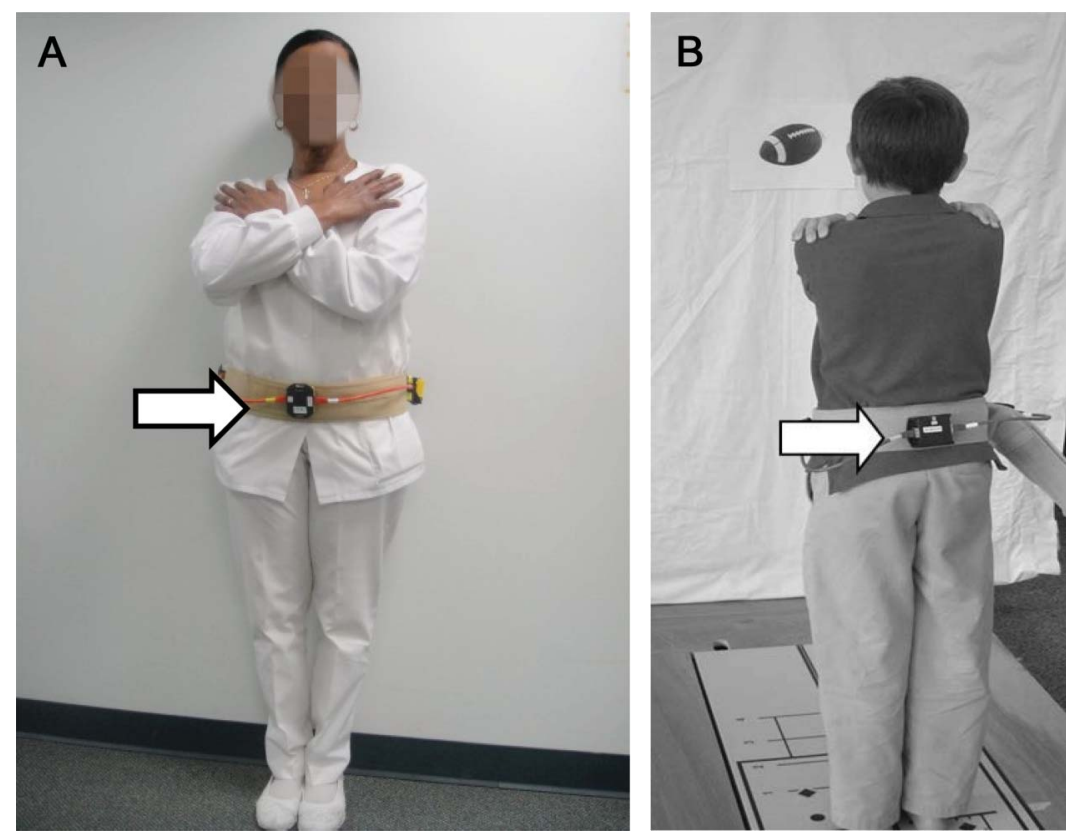

most subjects $(\mathrm{n}=206)$ on the same day after a short rest (minimum of 25 minutes). Subjects also completed posturography sensory organization testing (SOT) (higher values indicate less sway), ${ }^{27}$ with concurrent BAM to examine validity.

To examine the impact of accelerometer placement for children, whose locus of balance control is different than adults, ${ }^{3,28} 3.0$ - to 8.5 year-old children completed testing with the device at the waist and again with the device placed at the upper thoracic level.

Statistical analysis. Reliability (ICCs) was calculated between the test and retest trials at 40,50, and 60 seconds. BAM was compared with COP measures using a Pearson correlation coefficient. Concurrent validity of BAM scores with those obtained from the SOT was evaluated with a Spearman nonparametric correlation coefficient. SOT and BAM scores of subjects who could not complete the task because of a loss of balance were assigned a score equal to 3 SDs below the mean (age-group matched). Results obtained from those with and without $\mathrm{VH}$ (confirmed as above) were compared to determine validity using a $t$ test for independent samples. Mean age group differences on BAM scores were tested using a 1 -way analysis of variance separately within pediatric and adult age ranges.

RESULTS Dynamic visual acuity. Examination of successful completion rates revealed that $100 \%$ of individuals 13 years and older completed ETDRS testing, and 99\% of children 5 through 12 years completed HOTV and Lea testing. Furthermore, among the 3- and 4-yearolds, $91 \%$ and $85 \%$ completed static testing using Lea and HOTV optotypes, respectively. However, in the dynamic condition, only $74 \%$ and $69 \%$ were able to complete testing using the Lea and HOTV optotypes, respectively. There was excellent correlation between optotypes for HOTV and ETDRS $(r \geq$ $0.93, p=0.001)$ and for Lea and ETDRS $(r=0.90$, $p=0.001)$. Furthermore, there was good correlation $(r=0.78, p=0.001)$ of the NIH Toolbox static ETDRS scores with those from the ETDRS chart testing with a lightbox. Eighty-two percent of subjects with pathology were aged 9 years or older, resulting in minimal variance of scores obtained from the younger groups (Lea and HOTV). The significantly larger scores obtained by those with pathology resulted in a greater variance in the age groups including these subjects. Therefore, the lack of subjects with pathology in the younger groups would contribute to minimal variance and the low ICC values, and an underestimation of reliability for the dynamic test in the younger groups. However, scores achieved by children older than 10 years and adults were reliable (table 1).

DVA scores differed between those with and without $\mathrm{VH}$ ( $p \leq 0.001$ for adults; $p \leq 0.1$ for ETDRS optotype in children). Effect sizes (mean differencel $\mathrm{SD}$ ) ranged from 0.80 to 1.84 . Furthermore, dynamic testing with HOTV, Lea, and ETDRS had fair to good sensitivity $(50 \%, 67 \%$, and $73 \%$, respectively) and specificity $(73 \%, 63 \%$, and $69 \%$, respectively) and excellent negative predictive value ( $\geq 96 \%$ for all).

Balance Accelerometry Measure. Review of the rates of successful completion on each condition by age revealed that most healthy individuals older than 8 years could complete conditions 1 through 6 . The majority of children 3 through 5.9 years completed conditions 1 through 4, and those 6 through 8 years completed conditions 1 through 5. Results of the ICCs support that analysis of only 40 seconds of BAM data was needed to yield reliable data for children and adults (table 2). It must be noted that because of minimal variance (low number of subjects with pathology), results are likely an underestimation of reliability.

The correlations of NPL and COP recordings ranged from poor to excellent. For children, $r$ values ranged from 0.42 to 0.85 , and were best with placement of the accelerometer at the waist. For adults, $r$ values ranged from 0.42 to 0.70 across age groups and trial.

Correlation of scores from BAM condition 4 (standing on foam with eyes closed) and comparable posturography condition 5 (standing on sway-referenced support surface with eyes closed) was moderate for children and adults $(r=-0.48, p=0.04$; and $r=-0.42, p=$ 0.01 , respectively). These are the conditions believed to be most dependent on vestibular function for balance.

The small number of subjects with pathology (6 children and 18 adults) suggests low power. Despite this, for adults, the NPL measure differed between those with and without pathology on conditions 2 $(p=0.02), 5(p=0.04)$, and $6(p=0.05)$, with a trend for significance on $4(p=0.10)$. For children, scores differed only on condition $6(p=0.001)$, with a trend for significance on condition $4(p=0.09)$. 
Figure 3 Age effects from Balance Accelerometry Measure condition 4. Scores were optimal between 18 and 35 years of age

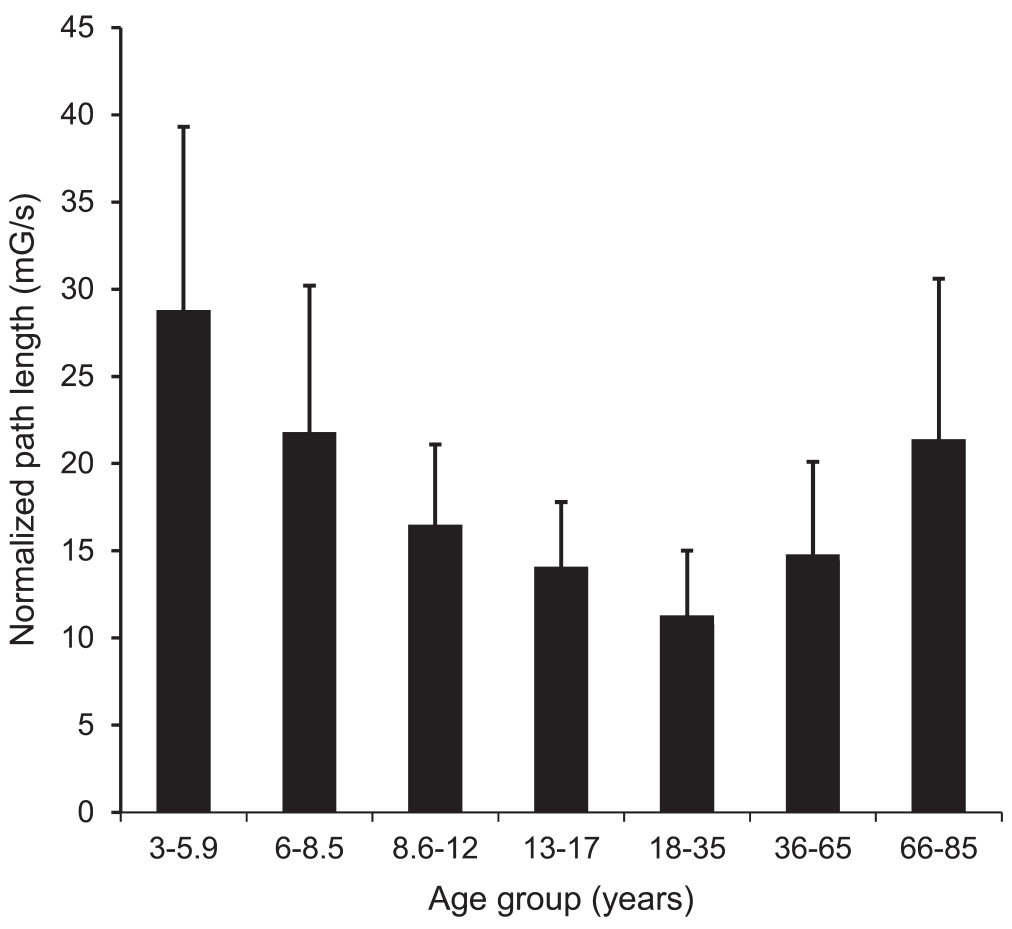

The NPL measure also reflected age-related effects (figure 3).

DISCUSSION Test choice for NIH Toolbox. Because of the slightly higher correlation of ETDRS and HOTV scores, they are the default sets in the NIH Toolbox for individuals aged 8 through 85 years, and 3 through 7 years, respectively. Lea optotype set will be made available for use. Completion rates on the SVA test were limited by cooperation of the youngest groups. Dynamic test completion rates of the younger children were affected by the dual task requirement (e.g., moving the head and identifying symbol). Consequently, rates were better with the use of Lea symbols. We acknowledge that although passive head movement is more specific to vestibular function, active movement was chosen to ensure that the test was independent of the experience of the tester, and the device assured proper velocity of head movement.

The moderate correlation of BAM and SOT scores may be attributable to the shortened duration (20 seconds) of posturography testing, resulting in less stable NPL measures. Interestingly, the lowest correlations were in the older child group (13-17 years). Two issues may explain this: 1) this is a critical period in balance development, particularly for use of vestibular information ${ }^{3,28}$; and 2) during this age period, children experience significant growth and body morphology change. Despite this, measures obtained from the BAM are reliable and valid, based on results presented here. Final tool recommendations are that: 1) all conditions be retained for children 8 years and older and adults, 2) conditions 1 to 4 be retained for children younger than 8 years, 3) the device be at the waist for all age levels, and 4) each subject complete 1 trial (second trial offered only as needed).

CONCLUSION Because of the small sample of subjects with $\mathrm{VH}$, and because most children with $\mathrm{VH}$ had unilateral chronic conditions and thus had likely compensated (learned to use remaining vestibular function and substitute strategies to balance), interpretation of these results for potential clinical use of the DVA and BAM is limited. However, the data support that the DVA and BAM tests meet the requirements of the NIH Toolbox: they are of low cost, can be completed in less than 5 minutes, and are appropriate for use with individuals 3 through 85 years of age. The NIH Toolbox DVA test is easy to administer and provides valid and reliable testing of visual acuity with head still or moving quickly. The NIH Toolbox BAM is reliable and valid for measuring balance and assists in screening for vestibular impairment. Both tests are sensitive to age-related changes. Further study with a larger number of children and adults with confirmed vestibular pathology is needed to firmly establish test sensitivity and specificity. Normative data collection and analyses on a large number of subjects across the lifespan have been completed.

\section{AUTHOR CONTRIBUTIONS}

Dr. Rine: study concept and design, study supervision, acquisition of data, manuscript writing, data interpretation. Dr. Schubert and Dr. Whitney: study concept and design, acquisition of data, data interpretation, critical revision of the manuscript for important intellectual content. Mr. Roberts: study concept and design, acquisition of data. Dr. Redfern: study concept and design, acquisition of data, data interpretation. Dr. Musolino: study concept and design. Ms. Roche: acquisition of data, data reduction, data interpretation. Mr. Steed: study concept and design, acquisition of data, data interpretation. Ms. Corbin: acquisition of data, reviewing the manuscript for accuracy. Mr. Lin: acquisition of data. Dr. Marchetti and Ms. Beaumont: analysis and interpretation. Dr. Carey, Dr. Shepard, Dr. Jacobson, Dr. Wrisley, Mr. Hoffman: critical revision of the manuscript for important intellectual content. Mr. Furman: acquisition of data, reviewing the manuscript for accuracy. Dr. Slotkin: study concept and design, study supervision, data interpretation, critical revision of the manuscript for important intellectual content.

\section{ACKNOWLEDGMENT}

The authors extend appreciation to Rohit Varma, MD, and Roberta McKean-Cowdin, PhD, of the University of Southern California for their expert contribution regarding vision acuity testing, and to Susan Magasi, OTR, PhD, of Northwestern University for contributions and collaboration on development of the BAM protocol.

\section{STUDY FUNDING}

This study was funded in whole or in part with Federal funds from the Blueprint for Neuroscience Research, NIH, under contract no. HHS-N260-2006-00007-C. 


\section{DISCLOSURE}

R.M. Rine has received travel reimbursement and honoraria from the British Audiological Society, the Royal Society of Medicine, the Hong Kong Physical Therapy Association, Emory University, Mayo Clinic, and the American Physical Therapy Association, served on the Scientific Review Committee of the Foundation for Physical Therapy Research, and was funded by NIH grant 5R44DC8022-3. M. Schubert was funded by $\mathrm{NIH}$ grant K23 007926, has worked as a consultant for a legal proceeding, and holds provisional patent C10585-P10585-02 (02240-283664). S. Whitney is a consultant for Visual Health Information, receives royalties from Oxford Press, and has received honoraria from the American Physical Therapy Association. D. Roberts is funded by NIH grants R21EY019713, R01EY019347, R01EY001849 DOC H, and R21NS059830. M. Redfern is funded by NIH grants R01OH008986, P30 AG024827, and R01 AG03111803, and by NSF grants CNS-0931595, CNS-0931999, and NSF-260116A. He holds US patent nos. 10/840,791 and 61/412,690 (which are not related to the current manuscript). M. Musolino reports no disclosures. J. Roche received funding from NSF grant CNS0964581. D. Steed received partial funding for a project from Robert Bosch, LLC. B. Corbin and C.-C. Lin report no disclosures. G. Marchetti is a consultant for Eli Lilly Pharmaceuticals and received funding for a trip to Indianapolis, IN as part of consulting services. G. Marchetti has in the past received research support from the Pittsburgh Foundation, the Arthritis Foundation, and the Saunders Corporation. J. Beaumont served as a consultant for NorthShore University Health Systems, FACIT.org, and Georgia Gastroenterology Group PC, and has received funding for travel as an invited speaker at the North American Neuroendocrine Tumor Symposium. J. Carey has been funded by NIH grants R01 DC005040, R01 DC002390, R01 DC009255, and R01 DC006296. In addition, he is a paid consultant for Otonomy and has provided expert witness testimony for approximately 3 medicolegal cases. N. Shepard has received travel reimbursement, book royalty and honoraria from the University of Nebraska, Mayo Clinic, University of Southampton, Emory University, American Academy of Otolaryngology, NeuroCom International Inc., MicroMedical Corp., Vanderbilt University, University of Cape Town South Africa, and Plural publishing. G. Jacobson is a consultant for the company Interacoustics. He receives royalties from Thomson Delmar Learning (Handbook of Balance Function Testing) and Plural Publishing (Balance Function Assessment and Management). He receives compensation for his role as Editor-in-Chief of the Journal of the American Academy of Audiology (American Academy of Audiology). D. Wrisley was funded by the Foundation for Physical Therapy and the New York Physical Therapy Association and served as an educator for NeuroCom International. H. Hoffman,. G. Furman, and J. Slotkin report no disclosures. Go to Neurology.org for full disclosures.

Received June 6, 2012. Accepted in final form August 30, 2012.

\section{REFERENCES}

1. Wei D, Hain TC, Proctor LR. Head-shaking nystagmus: associations with canal paresis and hearing loss. Acta Otolaryngol 1989;108:362-367.

2. Hirabayashi S, Iwasaki Y. Developmental perspective of sensory organization on postural control. Brain Dev 1995;17: 111-113.

3. Rine RM, Rubish K, Feeney C. Measurement of sensory system effectiveness and maturational changes in postural control in young children. Pediatr Phys Ther 1998;10:16-22.

4. Gazzola JM, Gananca FF, Aratani MC, Perracini MR, Gananca MM. Clinical evaluation of elderly people with chronic vestibular disorder. Braz J Otorhinolaryngol 2006; 72:515-522.

5. Schubert MC, Migliaccio AA, Clendaniel RA, Allak A, Carey JP. Mechanism of dynamic visual acuity recovery with vestibular rehabilitation. Arch Phys Med Rehabil 2008;89:500-507.

6. Herdman S, Tusa RJ, Blatt P, Suzuki A, Venuto PJ, Roberts D. Computerized dynamic visual acuity test in the assessment of vestibular deficits. Am J Otol 1998;19:790-796.
7. Schubert MC, Herdman SJ, Tusa RJ. Functional measure of gaze stability in patients with vestibular hypofunction. Ann NY Acad Sci 2001;942:490-491.

8. Grossman GE, Leigh RJ. Instability of gaze during locomotion in patients with deficient vestibular function. Ann Neurol 1990;27:528-532.

9. Grossman GE, Leigh RJ, Bruse EN, Huebner WP, Lanska DJ. Performance of the human vestibuloocular reflex during locomotion. J Neurophysiol 1989;62:264-272.

10. Hillman EJ, Bloomberg JJ, McDonald PV, Cohen HS. Dynamic visual acuity while walking in normals and labyrinthine-deficient patients. J Vestib Res 1999;9:49-57.

11. Brookouser PE, Cyr DG, Peters JE, Schulte LE. Correlates of vestibular evaluation results during the first year of life. Laryngoscope 1991;101:687-694.

12. Braswell J, Rine RM. Evidence that vestibular hypofunction affects reading acuity in children. Int J Pediatr Otorhinolaryngol 2006;70:1957-1965.

13. Mirka M, Black FO. Clinical application of dynamic posturography for evaluating sensory integration and vestibular dysfunction. Neurol Clin 1990;8:351-359.

14. Dichigans J, Deiner HC. The use of short-and long-latency reflex testing in leg muscles of neurological patients. In: Struppler A, Weindl A, editors. Clinical Aspects of Sensory Motor Integration. Berlin: Springer-Verlag; 1987:165-175.

15. Allum JHJ, Pfaltz CR. Influence of bilateral and acute unilateral peripheral vestibular deficits on early sway stabilizing responses in human tibialis anterior muscles. Acta Otolaryngol Suppl 1984;406:115-119.

16. Allum JH, Bloem BR, Carpenter MG, Honegger F. Differential diagnosis of proprioceptive and vestibular deficits using dynamic support-surface posturography. Gait Posture 2001;14:217-226.

17. Allum JHJ, Honegger F, Acuna H. Differential control of leg and trunk muscle activity by vestibulo-spinal and proprioceptive signals during human balance corrections. Acta Otolaryngol 1995;115:124-129.

18. Herdman SJ, Sandusky AL, Hain TC, Zee DS, Tusa RJ. Characteristics of postural stability in patients with aminoglycoside toxicity. J Vestib Res 1994;4:71-80.

19. Rine RM, Spielholz NI, Buchman C. Postural control in children with sensorineural hearing loss and vestibular hypofunction: deficits in sensory system effectiveness and vestibulospinal function. In: Duysens J, Smits-Engelsman BCM, Kingma H, editors. Control of Posture and Gait. Amsterdam: Springer-Verlag; 2001:40-45.

20. Shumway-Cook A, Horak FB. Assessing the influence of sensory interaction on balance. Phys Ther 1986;66: 1548-1550.

21. Rine RM, Roberts D, Corbin B, et al. New portable tool to screen vestibular and visual function: National Institutes of Health Toolbox Initiative. J Rehabil Res Dev 2012;49: 209-220.

22. Cotter SA, Tarczy-Hornock K, Wang Y, et al. Visual acuity testability in African-American and Hispanic children: the multi-ethnic pediatric eye disease study. Am J Ophthalmol 2007;144:663-667.

23. Ferris FL, Kassoff A, Bresnick GH, Bailey I. New visual acuity charts for clinical research. Am J Ophthalmol 1982; 94:91-96.

24. Lindemann U, Moe-Nilssen R, Nicolai SF, Becker C, Chiari L. Assessment of balance in unsupported standing with elderly inpatients by force plate and accelerometers. Aging Clin Exp Res 2012;24:37-41. 
25. Maetzler W, Mancini M, Liepelt-Scarfone I, et al. Impaired trunk stability in individuals at high risk for Parkinson's disease. PLoS One 2012;7:e32240.

26. Whitney SL, Roche JL, Marchetti GF, et al. A comparison of accelerometry and center of pressure measures during computerized dynamic posturography: a measure of balance. Gait Posture 2011;33:594-599.
27. Monsell EM, Furman JM, Herdman SJ, Konrad HR, Shepard NT. Computerized dynamic platform posturography. Otolaryngol Head Neck Surg 1997;117: 394-398.

28. Shumway-Cook A, Woollacott MI. The growth of stability: postural control from a developmental perspective. J Mot Behav 1985;17:131-147. 


\title{
Neurology
}

\author{
Vestibular function assessment using the NIH Toolbox \\ RoseMarie M. Rine, Michael C. Schubert, Susan L. Whitney, et al. \\ Neurology 2013;80;S25-S31 \\ DOI 10.1212/WNL.0b013e3182872c6a
}

This information is current as of March 11, 2013

\begin{tabular}{|c|c|}
\hline $\begin{array}{l}\text { Updated Information \& } \\
\text { Services }\end{array}$ & $\begin{array}{l}\text { including high resolution figures, can be found at: } \\
\text { http://n.neurology.org/content/80/11_Supplement_3/S25.full }\end{array}$ \\
\hline References & $\begin{array}{l}\text { This article cites } 26 \text { articles, } 1 \text { of which you can access for free at: } \\
\text { http://n.neurology.org/content/80/11_Supplement_3/S25.full\#ref-list-1 }\end{array}$ \\
\hline Citations & $\begin{array}{l}\text { This article has been cited by } 2 \text { HighWire-hosted articles: } \\
\text { http://n.neurology.org/content/80/11_Supplement_3/S25.full\#\#otherarti } \\
\text { cles }\end{array}$ \\
\hline Subspecialty Collections & $\begin{array}{l}\text { This article, along with others on similar topics, appears in the } \\
\text { following collection(s): } \\
\text { All Neurotology } \\
\text { http://n.neurology.org/cgi/collection/all_neurotology } \\
\text { Vertigo } \\
\text { http://n.neurology.org/cgi/collection/vertigo }\end{array}$ \\
\hline Permissions \& Licensing & $\begin{array}{l}\text { Information about reproducing this article in parts (figures,tables) or in } \\
\text { its entirety can be found online at: } \\
\text { http://www.neurology.org/about/about_the_journal\#permissions }\end{array}$ \\
\hline Reprints & $\begin{array}{l}\text { Information about ordering reprints can be found online: } \\
\text { http://n.neurology.org/subscribers/advertise }\end{array}$ \\
\hline
\end{tabular}

Neurology ${ }^{\circledR}$ is the official journal of the American Academy of Neurology. Published continuously since 1951, it is now a weekly with 48 issues per year. Copyright (C 2013 American Academy of Neurology. All rights reserved. Print ISSN: 0028-3878. Online ISSN: 1526-632X.

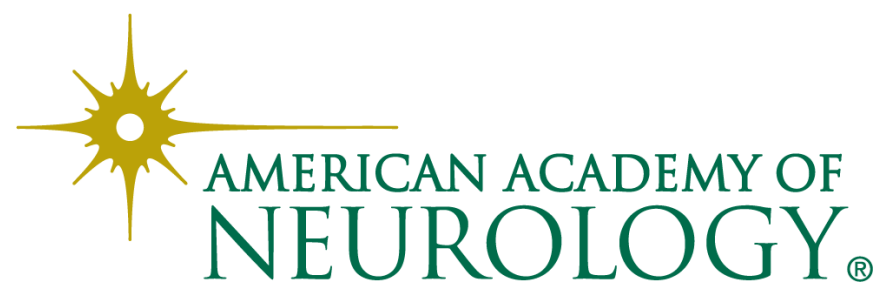

